\title{
ACCURACY OF MONTHLY AND SEASONAL FORECASTS GENERATED FOR THE TERRITORY OF LITHUANIA USING NOAA'S CLIMATE FORECAST SYSTEM VERSION 2
}

\author{
Arūnas BUKANTIS ${ }^{*}$ Gytis VALAIKA \\ Institute of Geosciences of Vilnius University, Vilnius, Lithuania \\ Received 09 October 2020; accepted 11 May 2021
}

\begin{abstract}
Highlights
Accuracy of monthly and seasonal air temperature and precipitation forecasts is dependent on the lead time and atmospheric circulation conditions at the time of initialization of the respective forecasts.

$>$ The accuracy of forecasts was performed in accordance with range, state and the absolute error of the respective predicted anomaly of air temperature and precipitation.
\end{abstract}

\begin{abstract}
The objective of this paper is to assess the accuracy of air temperature and precipitation monthly and seasonal forecasts generated for the territory of Lithuania using the NOAA's Climate Forecast System, version 2 (CFSv2) and to determine the atmospheric circulation conditions present at the time of initialization of the respective forecasts. The air temperature and precipitation data are obtained from three-month mean and monthly mean spatial anomalies during the period between 2012 and 2019. The accuracy of forecasts was performed in accordance with three criteria: range, state and the absolute error of the respective predicted anomaly. The study has shown that forecasts initialized 0-20 days in advance of the target month or season tend to be the most skilful. The accuracy of CFSv2 forecasts may be significantly impacted by the initial atmospheric circulation conditions present during the generation thereof. The study determined which phases of Arctic Oscillation (AO) and North Atlantic Oscillation (NAO) and which circulation types according to the Hess-Brezowsky classification are favourable/unfavourable for the monthly and seasonal forecasting of air temperature and precipitation.
\end{abstract}

Keywords: air temperature, atmospheric circulation, climate forecast system, environment monitoring, precipitations anomalies, accuracy of forecasts.

\section{Introduction}

The need for skilful monthly and seasonal forecasts of air temperature and precipitation anomalies have grown around the world. Such forecasts are necessary both for planning work of environment monitoring and making decisions in most economic sectors. For instance, having knowledge that summer will be relatively dry would allow for the accumulation of water reserves and the sowing of drought-resistant crops in the spring.

Dynamical and statistical models have been developed for seasonal forecasting. Weather and climate forecast centers such as the National Centers for Environmental Prediction (NCEP), the European Centre for MediumRange Weather Forecasts (ECMWF), Met Office's seasonal forecast system GloSea5 and other make dynamical predictions using fully coupled ocean-atmosphere general circulation models (GCMs). These models have demonstrated skill in forecasting at global or continental scales (Tian et al., 2014) but it is too early to claim that current long-range models are perfected to a sufficient degree. Forecasts are often unreliable even when they have been initialized for the next month, or the next three-month period, let alone for longer stretches of time (Weart, 2008; Troccoli, 2010). Despite that, however, obvious progress has been made in forecasting the weather of upcoming months (Weisheimer \& Palmer, 2014; Baker et al., 2018a, 2018b). The last several years have seen a fairly rapid increase in the reliability of forecasting models, while newer versions currently under development, as well as our growing understanding of the complex atmospheric and water processes, give rise to the hope that over the next

*Corresponding author. E-mail: arunas.bukantis@gf.vu.lt 
decades weather forecasts for several months in advance could see some notable improvements (Barnston \& Tippett, 2013; Saha et al., 2014; Powers et al., 2017; Dobrynin et al., 2018). Successful seasonal forecasting of the winter $\mathrm{NAO} / \mathrm{AO}$ has been demonstrated recently by dynamical prediction systems (Scaife et al., 2014; Baker et al., 2018b). It is found that the initial upper stratospheric zonal wind anomaly contributes to winter North Atlantic Oscillation and Arctic Oscillation (NAO/AO) predictability through downward propagation of initial conditions (Nie et al., 2019; Lee et al., 2020a).

A major step forward in monthly and seasonal forecasting was taken in 2004 when NOAA's National Centers for Environmental Prediction (NCEP) introduced the first long-range forecasting model of its generation called CFSv1. This was the first quasi-global (i.e., not inclusive of polar and surrounding regions), fully digital oceanatmosphere-earth model used to conclude seasonal forecasts (Reeves \& Gemmill, 2004; Saha et al., 2006).

Progress in the area of long-range forecasting did not stop there. In March 2011, the NCEP introduced the new digital second-generation global ocean-atmosphere-earth model called CFSv2. The new model features much more advanced physics, improved resolution, and better overall accuracy of forecasting seasonal climate anomalies. Furthermore, it also includes a new four-level $(10,30,60$, and $100 \mathrm{~cm}$ ) soil model block (Saha et al., 2013), an interactive three-level ice sheet model (containing two sea ice levels and one of snow cover), and a $\mathrm{CO}_{2}$ concentration fluctuation model, because $\mathrm{CO}_{2}$ concentration in the CFSv1 model was fixed at the 1988 level (Peng et al., 2013). In addition, the already existent atmospheric part of the CFS model was provided with a prognostic cloud and liquid water model, a model of the annual cycle of solar radiation, the mountain blocking effect (highly important for the purposes of forecasting the amount of precipitation), and convective gravity wave drag (Sigmond et al., 2013, Saha et al., 2014). A new data assimilation system that improves consistency between the model, input data, and other initial conditions was developed specifically for the new CFSv2 model (National Academies of Sciences, Engineering, and Medicine, 2016). The CFSv2 model focussed mostly on forecasts of air temperature and precipitation anomalies based on reanalysis of data for the period between 1982 and 2010. Analyses of the accuracy of the CFSv2 model forecasts have shown a marked global and regional improvement, as compared to the old CFSv1 model (Yuan et al., 2011; Saha et al., 2013).

The accuracy of monthly and seasonal regional forecasts of air temperature and precipitation anomalies can be determined by the atmospheric circulation conditions present during the initialization of the respective forecast: sea level pressure, isobaric surface anomalies, and the blocking of western flows (Häkkinen et al., 2011, Weisheimer \& Palmer, 2014; Powers et al., 2017). The physical processes that can reduce forecast accuracy are generally associated with atmospheric instabilities and weather regime transitions. Their low frequency, large spatial scale, and sensitivity to tropical and stratospheric conditions point to processes that can matter for subseasonal predictions and beyond (Mariotti et al., 2020).

In North and Central Europe atmospheric circulation is mostly affected by processes taking place in the northern part of the Atlantic Ocean and the Arctic (Hahn et al., 2018; Kendzierski et al., 2018). As a physical body, the ocean accumulates significantly more thermal energy and releases it slower than the atmosphere, while sea glaciers in the Arctic cool the surrounding environment and give rise to circumpolar vortices (National Oceanic and Atmospheric Administration. Climate Prediction Center. National Weather Service [NOAA CPC NWS], 2020a, 2020b). The atmospheric pressure centres formed over the North Atlantic and Arctic oceans lead to various oscillations, two of which, namely the NAO and the AO, are the most relevant to the Baltic Sea Region. This occurs because the North Atlantic pattern also influences the position and strength of polar-front jet stream and therefore modulates the impact of the NAO/AO on e.g. temperature and precipitation over parts of Europe (Woollings \& Blackburn, 2012; Parker et al., 2019).

The strength of a spatial pattern of surface pressure variability and development of the atmospheric centres of action are influenced by different factors, such as fluctuations in solar activity, El Niño-Southern Oscillation (ENSO), Quasi-Biennial Oscillation (QBO), and others (Labitzke et al., 2006; DiNezio et al., 2017; Albers \& Newman, 2019). The effects of ENSO are felt across the globe, for instance, during the warm phase, atmospheric circulation in the North Atlantic region typically resembles the negative phase of the NAO (Li \& Lau, 2012) in winter. Other global-scale processes and feedbacks in the climate system are, of course, no less important. The impact of the $\mathrm{NAO} / \mathrm{AO}$ is also dependent on the QBO: the impact during the eastern phase of the QBO is felt in larger territories and reaches higher altitudes, whereas during the western phase of the QBO, the impact signal is more local (Kuroda 2007; Akstinas \& Bukantis, 2015). NAO fluctuations and the long-term anomalies thereof lead to conditions favourable to the development of long-term weather anomalies within the Baltic Sea Region (Bukantis \& Bartkeviciene, 2005; Mickevičius \& Bukantis, 2013). The impact of the $\mathrm{NAO} / \mathrm{AO}$ on weather conditions and forecast accuracy is at its strongest during the cold season. For example, verification results show that, in the medium range, ECMWF ensemble forecasts initiated in the negative phase of $\mathrm{NAO}$ are the most skilful and the least skilful forecasts are mainly associated with missing the transitions to a blocking regime circulation (Ferranti et al., 2015).

Although the AO resembles the North Atlantic Oscillation in many respects, it shows some unique characters in the Polar region and North Pacific. There are two main differences: the NAO has no centre of action in the Pacific, and the $\mathrm{AO}$ has a broader centre of action over the polar cap, giving it a more zonally symmetric appearance 
(Thompson \& Walace, 2000). Furthermore, the AO representing sea level pressure anomaly field over the domain poleward of $20^{\circ} \mathrm{N}$ of cold season is more strongly coupled to surface air temperature fluctuations over the Eurasian continent than the NAO (Wang et al., 2005; Gong et al., 2018; Lee et al., 2020a).

The atmospheric circulation patterns behind weather anomalies in different parts of Europe can be described using the Hess-Brezowsky classification (James, 2007; Planchon et al., 2009). Previous studies have found that if subtypes of meridional circulation (except for the trough over Central Europe) are present during the warm season, Lithuania tends to experience more frequent high temperature anomalies, and when these subtypes are present during the cold season, cold anomalies occur (Bukantis \& Paulauskaite, 2001). Meanwhile, significant precipitation usually happens in the presence of the cyclonic westerly subtype (WZ) of zonal circulation (Rimkus et al., 2011). Studies on the accuracy of CFSv2 model forecasts for small regions and the link of the accuracy with atmospheric circulation are still lacking. The aim of the present study was to assess the accuracy of air temperature and precipitation anomaly CFSv2 model forecasts (with a lead time of $0-170$ days) within the territory of Lithuania, as well as the atmospheric circulation conditions behind it in accordance with the NAO and AO indices, and HessBrezowsky classification data.

\section{Materials and methods}

Observed monthly air temperature and precipitation amount anomalies have been calculated from 18 Lithuanian meteorological stations (MS) (Figure 1). The study period was February 2012-January 2019. The initial data of the monthly precipitation amount and mean air temperature anomalies calculated with respect to the climatology of 1981-2010. In order to avoid potential microclimatic effects present at certain individual MS, the data obtained from all $18 \mathrm{MS}$ were used to calculate the mean territorial anomalies for the entire area of the Republic of Lithuania.

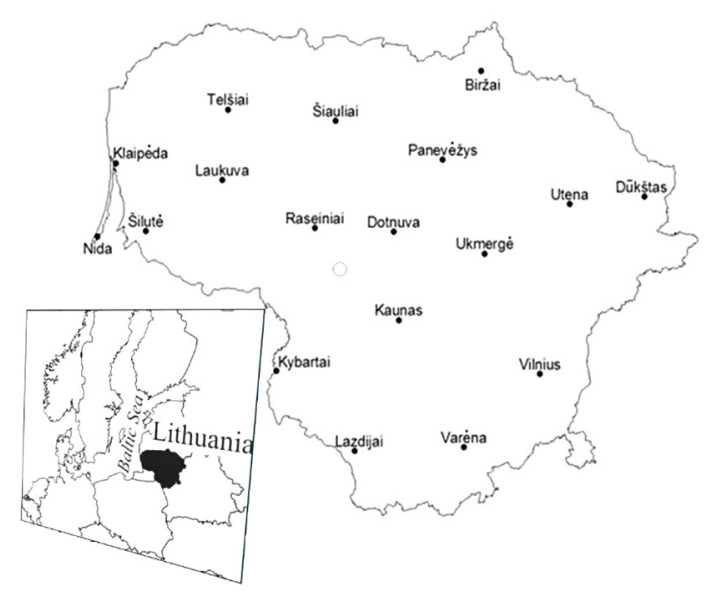

Figure 1. Locations of the Lithuanian meteorological stations whose data were used in the study

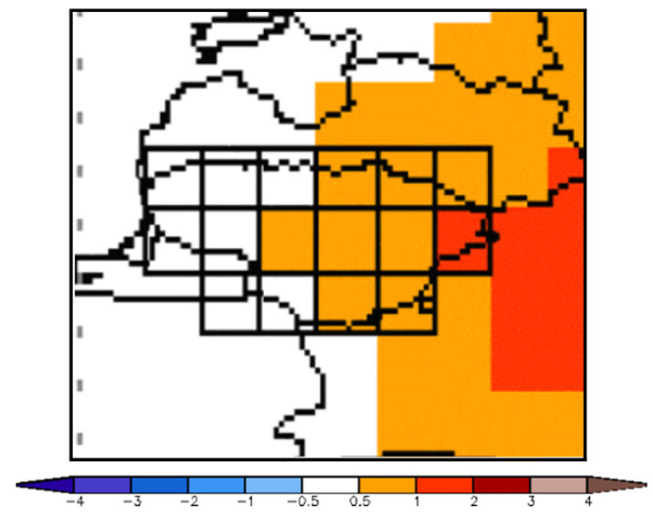

Figure 2. CFSv2 model cells which represent the territory of Lithuania and example of forecast temperature anomalies (K)

The study used digital data and maps related to the monthly and three-month air temperature and precipitation amount anomalies with lead times of 0-170 days contained in the data base of CFSv2 (NOAA CPC NWS, 2020c). The precipitation forecast units, expressed in millimetres per day in the CFSv2 model, were converted into precipitation amounts in millimetres over the span of one or three months.

The CFSv2 model uses $1 \times 1^{\circ}$ grid cells (the edge of the grid of the Lithuanian territory is approximately $84 \mathrm{~km}$ long and has an area of 7,100 $\mathrm{km}^{2}$ ). Based on the model grid, the Lithuanian territory was found to be present in 16 individual cells (Figure 2).

The range of air temperature and precipitation amount anomalies forecasted by CFSv2 for the territory of Lithuania was calculated at the beginning of the analysis. Each month of the year, as well as each three month-long season, had 18 forecasts ensembles with different lead times which were prepared every 10 days. Each forecast ensemble consists of 10 members from an initial period of 10 days. The forecast ensemble with the earliest lead time was initialized 179-170 days in advance of the beginning forecast period, the next forecast was initialized 169-160 days in advance, etc. The forecast ensemble with the latest lead time was initialized 9-0 days in advance, i.e., at the very beginning of the forecasted one-month and threemonths periods.

The accuracy of forecasts generated with the use of the CFSv2 model was assessed using three different methods:

1. In accordance with the correspondence between the ranges of the predicted anomaly $\left(F_{\min }\right.$ and $\left.F_{\max }\right)$ and observed mean spatial anomaly $\left(O_{i}\right)$. If observed anomaly $\left(O_{i}\right)$ falls within the predicted anomaly range $\left(F_{\min } \leq O_{i} \leq\right.$ $\left.F_{\max }\right)$, the prediction is considered valid.

2. In accordance with the correspondence between the state (plus/minus) of the predicted and observed anomalies: if $O_{i}<0$ and $F_{i}<0$ or $O_{i}>0$ and $F_{i}>0$, then it is a skilful forecast; if $O_{i}<0$ and $F_{i}>0$ or $O_{i}>0$ and $F_{i}<0$, then it is an unskilfully forecast.

3. In accordance with the absolute error $(A E)$ of the forecasted anomaly: 


$$
A E=\frac{1}{N} \sum_{i-1}^{N}\left|O_{i}-F_{i}\right|,
$$

where $O_{i}$ is the observed mean spatial anomaly, $F_{i}$ is the nearest value of the predicted interval, and $N$ is the sample size verification. If the forecast is perfectly accurate, then $A E=0$.

The present study also analyses the relationship between the skill of forecasts and atmospheric circulation prevailing at the time of initialization (initial a period of 10 days) of the respective forecasts. Circulation was analysed using data for each individual day, namely the standardised North Atlantic Oscillation (NAO) and Arctic Oscillation ( $\mathrm{AO}$ ) indices, and the types of Hess-Brezowsky classification.

The NAO index is based on the surface sea-level pressure difference between the Subtropical (Azores) High and the Subpolar (Iceland) Low. The positive phase of the NAO reflects below-normal pressure across the high latitudes of the North Atlantic and above-normal pressure over the central North Atlantic, the eastern United States and Western Europe. The negative phase reflects an opposite pattern of pressure anomalies over these regions. Both phases of the NAO are associated with changes in the intensity and location of the North Atlantic jet stream and storm tracks, and in large-scale modulations of zonal and meridional heat and moisture transport (NOAA CPC NWS, 2020a).

$\mathrm{AO}$ index is obtained by projecting the $\mathrm{AO}$ loading pattern to the daily anomaly $1000 \mathrm{mb}$ height field over $20^{\circ} \mathrm{N}-$ $90^{\circ} \mathrm{N}$ latitude. The AO loading pattern has been chosen as the first mode of Empirical Orthogonal Function analysis using monthly mean $1000 \mathrm{mb}$ height anomaly data from 1979 to 2000 over $20^{\circ} \mathrm{N}-90^{\circ} \mathrm{N}$. When the $\mathrm{AO}$ is in its positive phase, a ring of strong winds circulating around the North Pole acts to confine colder air across Polar Regions. This belt of winds becomes weaker and more distorted in the negative phase of the AO, which allows an easier southward penetration of colder, arctic air masses and increased storminess into the mid-latitudes (NOAA CPC NWS, 2020b).

Table 1. List of Hess-Brezowsky circulation types (Werner \& Gerstengarbe, 2010)

\begin{tabular}{|l|l|l|}
\hline $\begin{array}{c}\text { Groups of } \\
\text { circulation } \\
\text { types }\end{array}$ & \multicolumn{1}{|c|}{ Major types (GWT) } & \multicolumn{1}{|c|}{ Subtypes (GWL) } \\
\hline Zonal & Westerly circulations & $\begin{array}{l}\text { WA, WZ, WS, } \\
\text { WW }\end{array}$ \\
\hline Mixed & $\begin{array}{l}\text { South-Westerly circulations } \\
\text { North-Westerly circulations } \\
\text { High over Central Europe } \\
\text { Low over Central Europe }\end{array}$ & $\begin{array}{l}\text { SWA, SWZ } \\
\text { NWA, NWZ } \\
\text { HMM BM } \\
\text { TMeridional }\end{array}$ \\
\hline $\begin{array}{l}\text { Northerly circulations } \\
\text { Easterly circulations }\end{array}$ & $\begin{array}{l}\text { NA, NZ, HNA, } \\
\text { HNZ, HB, TRM } \\
\text { NEA, NEZ, HFA, } \\
\text { HFZ, HNFA, } \\
\text { HNFZ, SEA, SEZ } \\
\text { SA, SZ, TB, TRW }\end{array}$ \\
\hline
\end{tabular}

The Hess-Brezowsky classification comprises the following three categories: 1) groups of circulation types (zonal, mixed, and meridional), 2) major types (GWT), and 3) subtypes (GWL) (Werner \& Gerstengarbe, 2010). The list of Hess-Brezowsky circulation types is given in Table 1 . The Hess-Brezowsky classification catalogue is freely accessible at Wetterportal Orniwetter (Orniwetter, 2020).

In order to determine which of the atmospheric circulation conditions were favourable or unfavourable to the initialization of air temperature and precipitation amount anomaly forecasts, we first identified the percentage of accuracy and inaccuracy forecasts with lead times of 30, 20, 10 and 0 days. Each month of the year, as well as each three month-long season, had 4 CFSv2 forecasts ensembles with different lead times which were prepared every 10 days. The 1 st initial period (1st ensemble) is from the earliest 10 days (39-30 days before forecast period), the 2nd initial period (2nd ensemble) is from the second earliest 10 days (29-20 days before forecast period), the $3 \mathrm{rd}$ initial period (3rd ensemble) is 19-10 days before forecast period and the 4 th period (4th ensemble) is from the latest 10 days (0-9 days before forecast period). Then we calculated the average NAO and AO indices for the respective 10-day periods. An analogous method was also applied to analyse the relationships between forecast accuracy and the Hess-Brezowsky classification. It was determined which groups of circulation types and major types recorded during the initialization of accuracy and inaccuracy forecasts concluded using CFSv2. The relationships between circulation conditions and the accuracy of forecasts with lead times of over 30 days were not analysed due to the low accuracy thereof.

\section{Results}

\subsection{Verification of monthly spatial anomalies forecasts}

The present section analyses the accuracy of forecasts of monthly-mean air temperature and monthly precipitation amount spatial anomalies generated using CFSv2 for the territory of Lithuania between 2012 and 2019.

Figure 3 depicts the variable accuracy of the monthlymean air temperature forecasts generated using CFSv2, 0-170 days prior to the forecasted month. As can be seen in the figure, the most accurate air temperature forecasts were obtained within 0 days before the beginning of the forecasted month (fractions of the correct forecasts by anomaly range was $48 \%$ and $71 \%$ by the type of anomaly). The skill of forecasts declines with lead times between 0 and 40 days, but remains relatively stable afterwards. The average accuracy for the entire study period was 31\% (by anomaly range) and $54 \%$ (by anomaly type). The smallest absolute error (error module), i.e., the difference between the actual and the forecasted air temperature values of temperature forecasts generated using CFSv2 was seen in forecasts initialized right before the forecasted month (lead time of 0 days), in which case the mean error was 


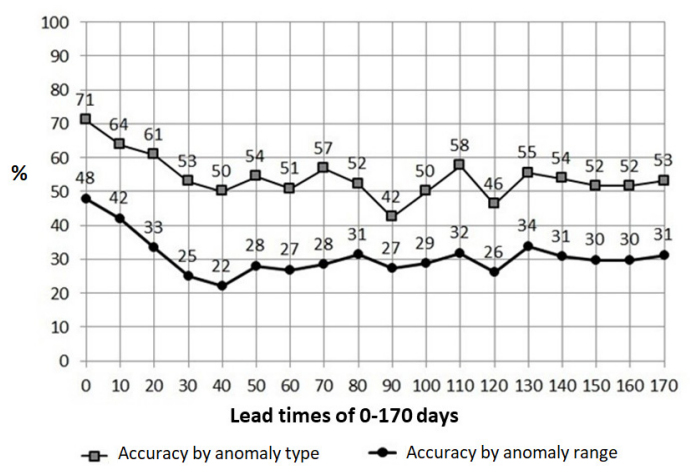

Figure 3. Accuracy (fractions of the correct forecasts in percent) of monthly-mean air temperature spatial anomaly forecasts generated using the CFSv2 model with different lead times for the territory of Lithuania

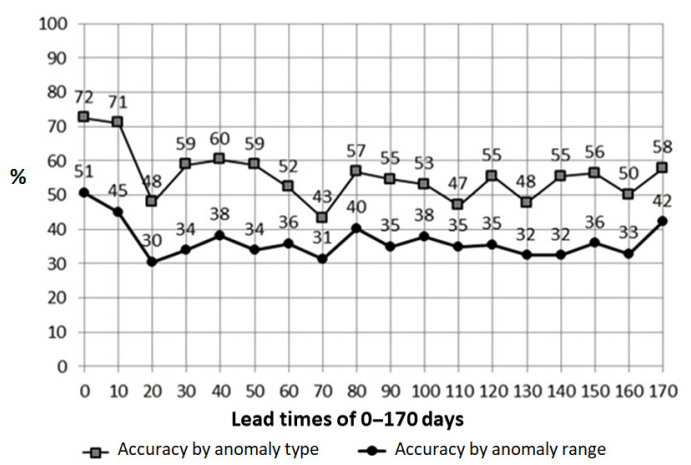

Figure 4 . The same as Figure 3 for monthly precipitation amount anomaly forecasts

$0.5^{\circ} \mathrm{C}$. The average error of the monthly-mean air temperature forecasts with different lead times prepared during the study period was $1.07^{\circ} \mathrm{C}$.

Figure 4 depicts the accuracy of the monthly precipitation amount anomaly forecasts 170 days or less prior to the forecasted month. It was determined that the most accurate monthly precipitation amount forecasts, just like in the case of air temperature forecasts, were obtained with 0 days left until the beginning of the forecasted month. The accuracy of such forecasts based on the anomaly range was $51 \%$ and $72 \%$ in accordance with the type of anomaly. During the entire period of study, the average fractions of the correct monthly precipitation amount anomaly forecasts with different lead times was 37\% (by anomaly range) and 55\% (by anomaly type), i.e., only marginally superior to analogous air temperature anomaly forecasts.

The smallest margin of error (error module $=7.9 \mathrm{~mm}$ per month) between the actual and the forecasted monthly precipitation amount anomalies was found with 0 days left until the beginning of the forecasted month, while the margin of error of monthly precipitation amount anomaly forecasts with different lead times was $12.1 \mathrm{~mm}$ per month. As compared to the climatology of 1981-2010, the margin of error during the period between June and November was $10-13 \%$ (with 0 days lead times) and $15-20 \%$ (with different lead times) of the monthly precipitation amount. During the period between December and May, it was characterised by a smaller amount of monthly precipitation, $14-26 \%$ and $22-40 \%$, respectively.

\subsection{Verification of the seasonal (three-month mean) spatial anomalies forecasts}

This section analyses the accuracy of forecasts of the seasonal (three-month mean) air temperature and threemonth precipitation amount spatial anomaly forecasts generated using CFSv2 for the territory of Lithuania between 2012 and 2019.

Figure 5 depicts the variable accuracy of the seasonal air temperature forecasts generated using CFSv2 170 days or less prior to the forecasted season. Calculations have shown that the best accuracy seasonal air temperature forecasts were obtained $0-10$ days prior to the forecasted season, in which case the fractions of the correct forecasts by anomaly range reached $46-51 \%$ and $66-69 \%$ by the type of anomaly. The average accuracy of the three-month mean air temperature anomaly forecasts with different lead times was, $39 \%$ and $57 \%$, respectively, in accordance with both criteria. Compared to monthly air temperature forecasts, seasonal forecasts are more accurate by several percentage points. Analyses have shown that the lowest absolute error $\left(0.34^{\circ} \mathrm{C}\right)$ in the forecasted seasonal air temperature anomalies was obtained with the minimum lead time, i.e., 0 days prior to the forecasted season. Warmerthan-usual seasons allow for more skill forecasting (mean absolute error $0.55^{\circ} \mathrm{C}$ ) than colder-than-normal seasons (mean absolute error $0.89^{\circ} \mathrm{C}$ ). The average margin of absolute error of the seasonal air temperature forecasts with different lead times was $0.49^{\circ} \mathrm{C}$, i.e., more than two times smaller than that of monthly air temperature forecasts.

Figure 6 depicts the variable accuracy of the threemonth mean precipitation amount anomaly forecasts 170 days or less prior to the forecasted season. It was determined that the most skill precipitation amount forecasts were generated 0 and 160 days prior to the forecasted season - the accuracy of such forecasts reached $68 \%$ by anomaly range and $76 \%$ by the type of anomaly. The average fractions of the correct three-month precipitation amount anomaly forecasts with different lead times was

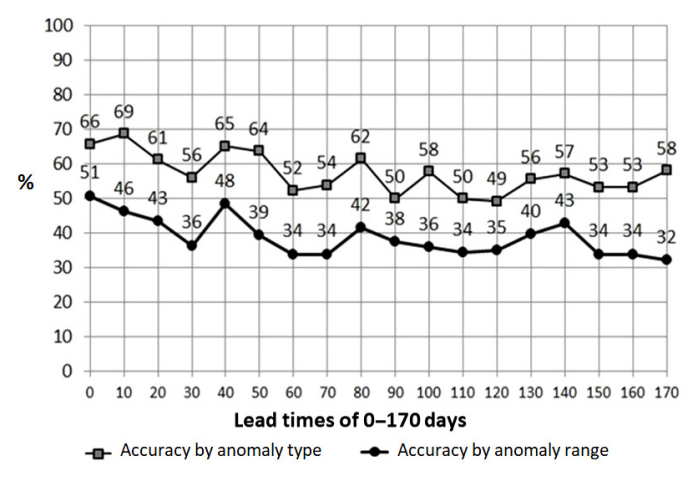

Figure 5. The same as Figure 3 for seasonal (three-month mean) air temperature spatial anomaly forecasts 


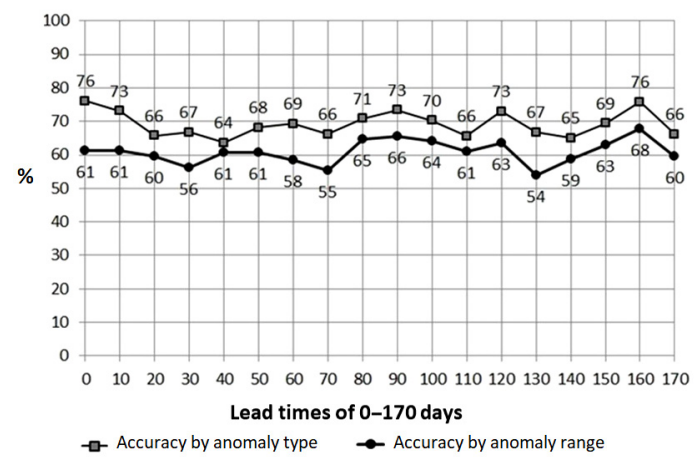

Figure 6. The same as Figure 3 for seasonal (three-month mean) precipitation amount spatial anomaly forecasts

$61 \%$ and $69 \%$, respectively in accordance with both criteria. Such accuracy values are much higher than in the case of monthly precipitation amount forecasts. The smallest margin of error (11.6-12.9 mm per season) between the actual and the forecasted values of seasonal amount of precipitation were also obtained in cases where the respective forecasts were generated 0 to 160 days prior to the forecasted season. The absolute error for precipitation amount in forecasts of arid seasons is $29 \mathrm{~mm}$ or $33 \mathrm{~mm}$ during anomalously humid seasons. The average margin of error of the accuracy of seasonal precipitation amount forecasts with different lead times was $14.4 \mathrm{~mm}$ per season. As compared to the climatology of 1981-2010, these margins of error constituted only $5-7 \%$ of the seasonal precipitation amount during the period between June and November, and $10-13 \%$ of the seasonal precipitation amount during the period between December and May. Even though the accuracy of seasonal forecasts is superior to that of monthly forecasts, it should be noted that the range of applicability of the former is much narrower.

\subsection{The relationship between the accuracy of forecasts generated using CFSv2 and atmospheric circulation}

An analysis of atmospheric circulation present during the initialization of the monthly air temperature forecasts (Table 2) has shown that the most skill forecasts were generated when the NAO index was strongly positive $>1$, leading to $58 \%$ accuracy, and the $\mathrm{AO}$ index was neutral between -0.5 and 0 , leading to $53 \%$ accuracy. Here, the accuracy of forecasts was assessed using the first method, i.e., based on the correspondence between the range of the predicted and observed anomalies. Unfavourable conditions were present when the NAO index was between -0.5 and 0 , leading to $29 \%$ accuracy, and the AO index was $<-0.5$, leading to $32-33 \%$ accuracy. According to the Hess-Brezowski classification, favourable conditions for generating forecasts are created by the westerly GWT (repetition 11.9\% above the norm), whereas unfavourable conditions arise given the dominance of the meridional GWT (northerly, easterly and southerly). The list of GWT and GWL is given in Table 1.
Results with regards to the seasonal air temperature forecasts were slightly different than monthly forecasts (Table 2). The most favourable $\mathrm{NAO}$ and $\mathrm{AO}$ indices for the purposes of forecasting were between -0.5 and 0 leading to $58-65 \%$ accuracy. Strongly negative $(<-1)$ and positive $(>1) \mathrm{NAO}$ and $\mathrm{AO}$ phases were found to be unfavourable to forecasting, leading to $21-42 \%$ accuracy of the seasonal air temperature forecasts. According to the Hess-Brezowski classification, conditions favourable to the initialization of seasonal air temperature forecasts were present given the dominance of meridional major types (their repetition $16.2 \%$ higher than multi-year norm) and the weakening of the zonal flow in the direction of the westerly major type (repetition $8 \%$ lower than multi-year norm), i.e., opposite to those present during the initialization of monthly air temperature forecasts.

Table 2. Favourable/unfavourable $\mathrm{NAO} / \mathrm{AO}$ indices intervals for the initialization of monthly and seasonal long-range air temperature forecasts for the territory of Lithuania using

CFSv2. Indices leading to better-than-average accuracy

(average fractions of the correct forecasts are $41 \%$ for monthly and $47 \%$ for seasonal forecasts) are depicted in light grey

\begin{tabular}{|l|c|c|c|c|c|c|}
\hline Indices & $<-1$ & $-1 \ldots-0.5$ & $-0.5-0$ & $0-0.5$ & $0.5-1$ & $>1$ \\
\hline Accuracy (\%) of monthly air temperature forecasts \\
\hline NAO & 47 & 45 & 29 & 37 & 48 & 58 \\
\hline AO & 32 & 33 & 53 & 42 & 46 & 38 \\
\hline Accuracy (\%) of easonal air temperature forecasts \\
\hline NAO & 40 & 56 & 58 & 50 & 39 & 21 \\
\hline AO & 28 & 57 & 65 & 40 & 53 & 42 \\
\hline
\end{tabular}

An analysis of atmospheric circulation present during the initialization of the monthly precipitation amount forecasts (Table 3 ) has shown that the most skill forecasts were generated given strongly positive $(>1)$ phases of the NAO. In such cases forecast accuracy was $58 \%$. Negative $\mathrm{NAO}$ indices $(<-0.5)$ were found to be unfavourable to the precipitation amount forecasts, leading to $32-40 \%$ accuracy. The most favourable $\mathrm{AO}$ indices to forecasting monthly precipitation amount were those between 0 and -1 , and $>0.5$, leading to $43-58 \%$ accuracy. Strongly negative $(<-1) \mathrm{AO}$ indices, as well as $\mathrm{AO}$ indices between 0 and 0.5 , were found to be unfavourable to the monthly precipitation amount forecasts, leading to $32-35 \%$ accuracy. According to the Hess-Brezowski classification, atmospheric circulation favourable to the initialization of precipitation amount forecasts was characterised by more frequent occurrence of zonal flow direction (westerly GWT), whereas unfavourable atmospheric circulation was typified by the strengthening (9.9\%) of meridional major types.

The most skill seasonal precipitation amount anomaly forecasts (Table 3) were found to have been generated in the presence of the positive phase of the NAO $(>0.5)$, leading to $68 \%$ accuracy, whereas negative NAO indices $(<-0.5)$ were the least favourable, leading to $47-53 \%$ accuracy. Strongly positive $(>1)$ and strongly negative $(<-1)$ 
Table 3. Favourable/unfavourable NAO/AO indices intervals for the initialization of monthly and seasonal long-range precipitation amount forecasts for the territory of Lithuania using CFSv2. Indices leading to better-than-average accuracy (average fractions of the correct forecasts are $42 \%$ for monthly and $61 \%$ for seasonal forecasts) are depicted in light grey

\begin{tabular}{|l|c|c|c|c|c|c|}
\hline Indices & $<-1$ & $-1 \ldots-0.5$ & $-0.5-0$ & $0-0.5$ & $0.5-1$ & $>1$ \\
\hline Accuracy (\%) of monthly precipitation amount forecasts \\
\hline NAO & 40 & 32 & 44 & 48 & 33 & 58 \\
\hline AO & 32 & 58 & 44 & 35 & 49 & 43 \\
\hline Accuracy (\%) of seasonal precipitation amount forecasts \\
\hline NAO & 47 & 53 & 63 & 56 & 68 & 68 \\
\hline AO & 69 & 65 & 53 & 52 & 62 & 67 \\
\hline
\end{tabular}

$\mathrm{AO}$ indices intervals were the most favourable to the initialization of seasonal precipitation amount anomaly forecasts, leading to $62-69 \%$ accuracy. Neutral values of the $\mathrm{AO}$ indices (i.e., values between -0.5 and 0.5 ) were the least favourable to forecasting, leading to $52-53 \%$ forecast accuracy. According to the Hess-Brezowski classification, conditions favourable to the initialization of seasonal precipitation amount forecasts were characterised by the strengthening (11.4\% above multi-year norm) of the meridional GWT, whereas unfavourable conditions were typified by the strengthening ( $3.1 \%$ above multi-year norm) of the westerly GWT. We found no relationships between the accuracy of forecasts and the mixed group circulation types.

\section{Discussion and conclusions}

In summary, it may be argued that the most accurate forecasts generated for the territory of Lithuania using CFSv2 were concerned with precipitation amount anomalies (both monthly and seasonal) followed by forecasts of seasonal and monthly air temperature. Of all the forecasted parameters examined, seasonal precipitation amount forecasts were most notable because their accuracy was highest by all assessment criteria. Results of the present study confirm the well-known truth about long-range forecasts with lead times of over 20 days, namely the accuracy of such forecasts is not yet sufficient, which means that they can be used on for practical purposes only after appropriate interpretation. The most skill forecasts are not the specific forecasted anomaly intervals, but their types, i.e., positive anomalies, negative anomalies, or situations close to the climatic norm.

The results of the analysis of accuracy of air temperature forecasts for the territory of Lithuania generated using CFSv2 do not always support the outcomes of the previous studies. However, in the publications of other authors, a different methodology and different criteria are used to assess the validity of seasonal forecasts, which makes it difficult to compare the obtained results (Weisheimer \& Palmer, 2014; Ferranti et al., 2015; Kendzierski et al., 2018; Lee et al., 2020b). For example, the accuracy of regional temperature and precipitation forecasts of the seasonal forecast system of the European Center for MediumRange Weather Forecasts (ECMWF) all winter predictions of temperatures over Northern Europe fall into the "marginally useful" category, whereas in summer the temperature forecasts over Europe are improved. Cold summer anomalies over Northern Europe classified to have "perfect" accuracy (Weisheimer \& Palmer, 2014). The results of the present study show that warmer-than-usual seasons allow for more skill forecasting than colder-thannormal seasons. The accuracy of precipitation forecasts generated using ECMWF for winters over Northern Europe is "not useful" for dry events and "marginally useful" for wet events. The accuracy of precipitation forecasts for dry summers over Northern Europe is notably "dangerously useless" and for wet events - "marginally useful" (Weisheimer \& Palmer, 2014). In Lithuania the absolute error for precipitation amount in forecasts of arid seasons generated using CFSv2 is less than during anomalously humid seasons. In summary, it can be preliminary stated that seasonal precipitation amount forecasts generated using CFSv2 for the territory of Lithuania are more skill when ECMWF seasonal forecast.

A detailed analysis of atmospheric circulation at the time of initialization of CFSv2 forecasts has shown a relationship between its accuracy with the phases of the NAO and $\mathrm{AO}$ indices. This has been established by other authors as well (Häkkinen et al., 2011; Albers \& Newman, 2019; Lee et al., 2020a). Therefore, based on information on NAO/AO indices at the time of initialization of monthly and seasonal long-range forecasts, their accuracy can be tentatively predicted.

The Hess-Brezowsky classification has been used in various studies assessing trends in frequencies, changes in event duration, and transition probabilities between GWL types but has never applied to climatological studies as favourable/unfavourable factor for the initialization of monthly and seasonal long-range forecasts. The study has shown that monthly air temperature and precipitation amount forecasts are more accurate given the predominance of westerly circulation types (in accordance with the Hess-Brezowsky classification) at the time of forecast initialization, while seasonal forecasts benefit mostly from the predominance of meridional major types. The skill of CFSv2 forecasts may be significantly impacted by the initial atmospheric circulation conditions present during the generation thereof. The latter aspect may be of significance in efforts to determine the reasons behind forecast inaccuracy, as well as for improving the accuracy of long-range forecasts.

\section{Acknowledgements}

The authors thank NOAA for the possibility to use the archives of the CFSv2 database during the research, as well as the Lithuanian Hydrometeorological Service for the provided climatic archive data. 


\section{References}

Akstinas, V., \& Bukantis, A. (2015). Quasi-biennial oscillation effect on climate indicators: Lithuania's case. Baltica, 28(1), 19-28. https://doi.org/10.5200/baltica.2015.28.03

Albers, J. R., \& Newman, M. (2019). A priori identification of skillful extratropical subseasonal forecasts. Geophysical Research Letters, 46(21), 12527-12536. https://doi.org/10.1029/2019GL085270

Baker, L. H., Shaffrey, L. C., \& Scaife, A. A (2018a). Improved seasonal prediction of UK regional precipitation using atmospheric circulation. International Journal of Climatology, 38(S1), e437-e453. https://doi.org/10.1002/joc.5382

Baker, L. H., Shaffrey, L. C., Sutton, R. T., Weisheimer, A., \& Scaife, A. A. (2018b). An intercomparison of skill and overconfidence/underconfidence of the wintertime North Atlantic Oscillation in multimodel seasonal forecasts. Geophysical Research Letters, 45(15), 7808-7817.

https://doi.org/10.1029/2018GL078838

Barnston, A. G., \& Tippett, M. K. (2013). Predictions of Nino3.4 SST in CFSv1 and CFSv2: A diagnostic comparison. Climate Dynamics, 41, 1615-1633.

https://doi.org/10.1007/s00382-013-1845-2

Bukantis, A., \& Bartkeviciene, G. (2005). Thermal effects of the North Atlantic Oscillation on the cold period of the year in Lithuania. Climate Research, 25(3), 221-228.

https://doi.org/10.3354/cr028221

Bukantis, A., \& Paulauskaite, S. (2001). Peculiarities of annual cycle of air temperature in Klaipeda and the character of atmospheric circulation processes. Geographical Yearbook, 34(2), 5-14.

DiNezio, P. N., Deser, C., Okumura, Y., \& Karspeck, A. (2017). Predictability of 2-year La Niña events in a coupled general circulation model. Climate Dynamics, 49, 4237-4261.

https://doi.org/10.1007/s00382-017-3575-3

Dobrynin, M., Domeisen, D. I. V., Müller, W. A., Bell, L., Brune, S., Bunzel, F., Düsterhus, A., Fröhlich, K., Pohlmann, H., \& Baehr, J. (2018). Improved teleconnection-based dynamical seasonal predictions of boreal winter. Geophysical Research Letters, 45(8), 3605-3614.

https://doi.org/10.1002/2018GL077209

Ferranti, L., Corti, S., \& Janousek, M. (2015). Flow-dependent verification of the ECMWF ensemble over the Euro-Atlantic sector. Quarterly Journal of the Royal Meteorological Society, 141(688), 916-924. https://doi.org/10.1002/qj.2411

Gong, H., Wang, L., Chen, W., \& Nath, D. (2018). Multidecadal fluctuation of the wintertime arctic oscillation pattern and its implication. Journal of Climate, 31(14), 5595-5608.

https://doi.org/10.1175/JCLI-D-17-0530.1

Hahn, L., Ummenhofer, C. C., \& Kwon Y.-O. (2018). North Atlantic natural variability modulates emergence of widespread Greenland melt in a warming climate. Geophysical Research Letters, 45(17), 9171-9178.

https://doi.org/10.1029/2018GL079682

Häkkinen, S., Rhines, P. B., \& Worthen, D. L. (2011). Atmospheric blocking and Atlantic multidecadal ocean variability. Science, 334(6056), 655-659.

https://doi.org/10.1126/science.1205683

James, P. M. (2007). An objective classification method for Hess and Brezowsky Grosswetterlagen over Europe. Theoretical and Applied Climatology, 88, 17-42. https://doi.org/10.1007/s00704-006-0239-3

Kendzierski, S., Czernecki, B., Kolendowicz, L., \& Jaczewski, A. (2018). Air temperature forecasts' accuracy of selected short- term and long-term numerical weather prediction models over Poland. Geofizika, 35(1), 19-37.

https://doi.org/10.15233/gfz.2018.35.5

Kuroda, Y. (2007). Effect of QBO and ENSO on the Solar cycle modulation of winter North Atlantic Oscillation. Journal of the Meteorological Society of Japan, 85(6), 889-898.

https://doi.org/10.2151/jmsj.85.889

Labitzke, K., Kunze, M., \& Bronnimann, S. (2006). Sunspots, the QBO and the stratosphere in the North Polar Region - 20 years later. Meteorologische Zeitschrift, 15(3), 355-363. https://doi.org/10.1127/0941-2948/2006/0136

Lee, D. Y., Lin, W., \& Petersen, M. R. (2020a). Wintertime Arctic Oscillation and North Atlantic Oscillation and their impacts on the Northern Hemisphere climate in E3SM. Climate Dynamics, 55, 1105-1124. https://doi.org/10.1007/s00382-020-05316-0

Lee, S. H., Lawrence, Z. D., Butler, A. H., \& Karpechko, A. Y. (2020b). Seasonal forecasts of the exceptional Northern Hemisphere winter of 2020. Geophysical Research Letters, 47(21), e2020GL090328. https://doi.org/10.1029/2020GL090328

Li, Y., \& Lau, N. C. (2012). Contributions of downstream eddy development to the teleconnection between ENSO and the atmospheric circulation over the North Atlantic. Journal of Climate, 25(14), 4993-5010.

https://doi.org/10.1175/JCLI-D-11-00377.1

Mariotti, A., Baggett, C., Barnes, E. A., Becker, E., Butler, A., Collins, D. C., Dirmeyer, P. A., Ferranti, L., Johnson, N. C., Jones, J., Kirtman, B. P., Lang, A. L., Molod, A., Newman, M., Robertson, A. W., Schubert, S., Waliser, D. E., \& Albers, J. (2020). Windows of opportunity for skilful forecasts subseasonal to seasonal and beyond. Bulletin of the American Meteorological Society, 101(5), E608-E625.

https://doi.org/10.1175/BAMS-D-18-0326.1

Mickevičius, V., \& Bukantis, A. (2013). Effects of the North Atlantic Oscillation on the Lithuanian climate. Vandens ükio inžinerija, 42(62), 5-13.

National Academies of Sciences, Engineering, and Medicine. (2016). Next Generation Earth System Prediction: Strategies for subseasonal to seasonal forecasts. The National Academies Press. https://doi.org/10.17226/21873

Nie, Y., Scaife, A. A., Ren, H.-L., Comer, R. E., Andrews, M. B., Davis, P., \& Martin, N. (2019). Stratospheric initial conditions provide seasonal predictability of the North Atlantic and Arctic Oscillations. Environmental Research Letters, 14(3), 034006. https://doi.org/10.1088/1748-9326/ab0385

National Oceanic and Atmospheric Administration. Climate Prediction Center. National Weather Service. (2020a). North Atlantic Oscillation (NAO). http://www.cpc.ncep.noaa.gov/ products/precip/CWlink/pna/nao.shtml

National Oceanic and Atmospheric Administration. Climate Prediction Center. National Weather Service. (2020b). Arctic Oscillation (AO). http://www.cpc.ncep.noaa.gov/products/ precip/CWlink/daily_ao_index/ao.shtml

National Oceanic and Atmospheric Administration. Climate Prediction Center. National Weather Service. NOAA CPC NWS. (2020c). Seasonal climate forecast from CFSv2. http://www.cpc.ncep.noaa.gov/products/CFSv2/CFSv2seasonal.shtml

Orniwetter. (2020). Wetterportal. http://www.orniwetter.info/ wetterlagenkalender/

Parker, T., Woollings, T., Weisheimer, A., O’Reilly, C. H., Baker, L., \& Shaffrey, L. (2019). Seasonal predictability of the winter North Atlantic Oscillation from a jet stream perspective. Geophysical Research Letters, 46(16), 10159-10167. https://doi.org/10.1029/2019GL084402 
Peng, P., Barnston, A. G., \& Kumar, A. (2013). A comparison of skill between two versions of the NCEP climate forecast system (CFS) and CPC's operational short-lead seasonal outlooks. Weather Forecast, 28(2), 445-462. https://doi.org/10.1175/WAF-D-12-00057.1

Planchon, O., Quénol, H., Dupont, N., \& Corgne, S. (2009). Application of the Hess-Brezowsky classification to the identification of weather patterns causing heavy winter rainfall in Brittany (France). Natural Hazards Earth System Sciences, 9(4), 1161-1173. https://doi.org/10.5194/nhess-9-1161-2009

Powers, J. G., Klemp, J. B., Skamarock, W. C., Davis, C. A., Dudhia, J., Gill, D. O., Coen, J. L., Gochis, D. J., Ahmadov, R., Peckham, S. E., Grell, G. A., Michalakes, J., Trahan, S., Benjamin, S. G., Alexander, C. R., Dimego, G. J., Wang, W., Schwartz, C. S., Romine, G. S., Liu, Z., Snyder, C., Chen, F., Barlage, M. J., Yu, W., \& Duda, M. G. (2017). The weather research and forecasting (WRF) model: Overview, system efforts, and future directions. Bulletin of the American Meteorological Society, 98(8), 1717-1737.

https://doi.org/10.1175/BAMS-D-15-00308.1

Reeves, R. W., \& Gemmill, D. D. (2004). Reflections on 25 years of analysis, diagnosis, and prediction. National Oceanic and Atmospheric Administration. Climate Prediction Center. US Government Printing Office.

Rimkus, E., Kazys, J., Bukantis, A., \& Krotovas, A. (2011). Temporal variation of extreme precipitation events in Lithuania. Oceanologia, 53(Suppl. 1), 259-277. https://doi.org/10.5697/oc.53-1-TI.259

Saha, S., Nadiga, S., Thiaw, C., Wang, J., Wang, W., Zhang, Q., Van den Dool, H. M., Pan, H.-L., Moorthi, S., Behringer, D., Stokes, D., Peña, M., Lord, S., White, G., Ebisuzaki, W., Peng, P., \& Xie, P. (2006). The NCEP Climate Forecast System. Journal of Climate, 19(15), 3483-3517. https://doi.org/10.1175/JCLI3812.1

Saha, S., Van den Dool, H. M., Zhang, Q., Mendez, M. P., \& Becker, E. (2013). NCEP Climate Forecast System version 2 (CFSv2) in the context of the US National Multi Model Ensemble (NMME) for seasonal prediction. In ECMWF Seminar on Seasonal Prediction, 3-7 September 2012, Shinfield Park, Reading (pp. 269-272). https://www.ecmwf.int/node/12062

Saha, S., Moorthi, S., Wu, X., Wang, J., Nadiga, S., Tripp, P., Behringer, D., Hou Y.-T., Chuang, H., Ek, M. I. M., Meng, J., Yang, R., Mendez, M. P., Van den Dool, H. M., Zhang, Q., Wang, W., Chen, M., \& Becker, E. (2014). The NCEP Climate Forecast System version 2. Journal of Climate, 27(6), 21852208. https://doi.org/10.1175/JCLI-D-12-00823.1
Scaife, A. A., Arribas, A., Blockley, E., Brookshaw, A., Clark, R. T., Dunstone, N., Eade, R., Fereday, D., Folland, C. K., Gordon, M., Hermanson, L., Knight, J. R., Lea, D. J., MacLachlan, C., Maidens, A., Martin, M., Peterson, A. K., Smith, D., Vellinga, M., Wallace, E., Waters, J., \& Williams, A. (2014). Skillful long-range prediction of European and North American winters. Geophysical Research Letters, 41(7), 2514-2519. https://doi.org/10.1002/2014GL059637

Sigmond, M., Scinocca, J. F., Kharin, V. V., \& Shepherd, T. G. (2013). Enhanced seasonal forecast skill following stratospheric sudden warmings. Nature Geoscience, 6(2), 98-102. https://doi.org/10.1038/ngeo1698

Tian, D., Martinez, C. J., Graham, W. D., \& Hwang, S. (2014). Statistical downscaling multimodel forecasts for seasonal precipitation and surface temperature over the Southeastern United States. Journal of Climate, 27(22), 8384-8411. https://doi.org/10.1175/JCLI-D-13-00481.1

Thompson, D. W. J., \& Wallace, J. M. (2000). Annular modes in the extratropical circulation. Part I: Month-to-month variability. Journal of Climate, 13(5), 1000-1016. https://doi. org/10.1175/1520-0442(2000)013<1000:AMITEC>2.0.CO;2

Troccoli, A. (2010). Seasonal climate forecasting. Meteorological Applications, 17(3), 251-268. https://doi.org/10.1002/met.184

Wang, D., Wang, C., Yang, X., \& Lu, J. (2005). Winter Northern Hemisphere surface air temperature variability associated with the Arctic Oscillation and North Atlantic Oscillation. Geophysical Research Letters, 32(16), 1-4. https://doi.org/10.1029/2005GL022952

Weart, S. R. (2008). The discovery of global warming. Revised and Expanded Edition. https://doi.org/10.4159/9780674417557

Weisheimer, A., \& Palmer, T. N. (2014). On the accuracy of seasonal climate forecasts. Journal of the Royal Society. Interface, 11, 20131162. https://doi.org/10.1098/rsif.2013.1162

Werner, P. C., \& Gerstengarbe, F.-W. (2010). Katalog der Großwetterlagen Europas (1881-2009) Nach Paul Hess und Helmuth Brezowsky. Potsdam Institut für Klimafolgenforschung, Potsdam. https://www.pik-potsdam.de/en/output/publications/ pikreports/summary-report-no.-119

Woollings, T., \& Blackburn, M. (2012). The North Atlantic jet stream under climate change and its relation to the NAO and EA patterns. Journal of Climate, 25(3), 886-902. https://doi.org/10.1175/JCLI-D-11-00087.1

Yuan, X., Wood, E. F., Luo, L., \& Pan, M. (2011). A first look at Climate Forecast System version 2 (CFSv2) for hydrological seasonal prediction. Geophysical Research Letters, 38(13), L13402. https://doi.org/10.1029/2011GL047792 